\title{
Clonal Karyotype Evolution Involving Ring Chromosome 1 with Myelodysplastic Syndrome Subtype RAEB-t Progressing into Acute Leukemia
}

\author{
Thomas Duell $^{a}$ Brigitte Poleck-Dehlin $^{a}$ Christoph Schmid $^{a}$ \\ Bettina Wunderlich $^{\mathrm{a}}$ Georg Ledderose $^{\mathrm{a}}$ Johann Mittermüller $^{\mathrm{b}}$ \\ Hans Jochen Kolb ${ }^{a, b}$ Helga Schmetzer ${ }^{a, b}$ \\ ${ }^{a}$ Department of Medicine III, Klinikum Grosshadern, University of Munich and ${ }^{\mathrm{b}}$ GSF - Research Center for \\ Environment and Health, Munich, Germany
}

\section{Key Words}

Acute myeloid leukemia • Bone marrow transplantation, allogeneic $\cdot$ Clonal evolution $\cdot$ Cytogenetics $\cdot$ Myelodysplastic syndrome $\cdot$ Ring chromosome $1 \cdot$ Stem cell transplantation - Donor lymphocyte infusion

\begin{abstract}
Karyotypic evolution is a well-known phenomenon in patients with malignant hematological disorders during disease progression. We describe a 50 -year-old male patient who had originally presented with pancytopenia in October 1992. The diagnosis of a myelodysplastic syndrome (MDS) FAB subtype RAEB-t was established in April 1993 by histological bone marrow (BM) examination, and therapy with low-dose cytosine arabinoside was initiated. In a phase of partial hematological remission, cytogenetic assessment in August 1993 revealed a ring chromosome 1 in 13 of 21 metaphases beside BM cells with normal karyotypes $[46, X Y, r(1)(p 35 q 31) / 46, X Y]$. One month later, the patient progressed to an acute myeloid leukemia
\end{abstract}

Thomas Duell and Brigitte Poleck-Dehlin contributed equally to this publication.
(AML), subtype M4 with 40\% BM blasts and cytogenetic examination showed clonal evolution by the appearance of additional numerical aberrations in addition to the ring chromosome $[46, X Y, r(1),+8,-21 / 45, X Y, r(1),+8,-21,-22 / 46$, $X Y]$. Intensive chemotherapy and radiotherapy was applied to induce remission in preparation for allogeneic bone marrow transplantation (BMT) from the patient's HLA-compatible son. After BMT, complete remission was clinically, hematologically and cytogenetically (normal male karyotype) confirmed. A complete hematopoietic chimerism was demonstrated. A relapse in January 1997 was successfully treated using donor lymphocyte infusion and donor peripheral blood stem cells (PB-SC) in combination with GM-CSF as immunostimulating agent in April 1997, and the patient's clinical condition remained stable as of January 2005. This is an interesting case of a patient with AML secondary to MDS. With the ring chromosome 1 we also describe a rare cytogenetic abnormality that predicted the poor prognosis of the patient, but the patient could be cured by adoptive immunotherapy and the application of donor's PB-SC. This case confirms the value of cytogenetic analysis in characterizing the malignant clone in hematological neoplasias, the importance of controlling the quality of an induced remission and of the detection of a progress of the disease.

Copyright (c) 2006 S. Karger AG, Basel

Helga Schmetzer, $\mathrm{PhD}$

Klinikum Grosshadern, Medical Department III

Marchioninistrasse 15, DE-81377 Munich (Germany)

Tel. +49 8970956135 or 3137, Fax +498970956137

E-Mail Helga.Schmetzer@med.uni-muenchen.de 


\section{Introduction}

Cytogenetic abnormalities are known to occur in bone marrow (BM) cells in about $50 \%$ of patients with myelodysplastic syndrome (MDS) and acute myeloid leukemia (AML) [1-3]. Clonal karyotype evolution is a well-known phenomenon in these patients, often preceding a clinical progression of the disease. This is why cytogenetic examinations make a valuable tool to estimate the prognosis; usually, patients with certain cytogenetic markers or with a complex karyotype or with a new arising marker in the course of the disease have a worse prognosis than those without a cytogenetic abnormality $[1,4]$. Ring chromosomes are genetic abnormalities occurring in leukemic and other neoplastic cells and are often related to a poorer prognosis $[5,6]$. Ring chromosomes have been described in patients with MDS [7] but so far no ring chromosome 1.

Despite the advent of new therapeutic agents, the prognosis of an MDS and secondary AML is still very poor [8]. Generally, secondary leukemias are harder to treat than primary malignancies. Bone marrow transplantation (BMT) is regarded as the only curative treatment for patients younger than 60 years [9]. We report an MDS (RAEB-t subtype) patient who had presented with a ring chromosome 1 , followed by a clonal evolution in BM cells, who had an early progress which could be treated by BMT and achieved a long-term remission after a relapse by adoptive immunotherapy using donor lymphocyte infusion (DLI) and donor peripheral blood stem cells (PB-SC).

\section{Case Report}

A 50-year-old male patient was admitted to our facility in April 1993 for a medical workup after outpatient blood examinations had shown persistent asymptomatic pancytopenia since October 1992. The $\mathrm{PB}$ revealed pancytopenias with $28 \times 10^{9} / 1$ leukocytes, $11 \mathrm{~g} / \mathrm{dl}$ hemoglobin, $68 \times 10^{9} / 1$ thrombocytes and $1 \%$ blast cells. BM examination revealed a blast count of 29 with $60 \%$ of those cells being peroxidase positive and $50 \%$ of them being esterase positive. Ringed sideroblasts or Auer rods were not detectable. According to the French-American-British (FAB) classification (table 1) [10], the disease was rated as an MDS subtype RAEB-t with transition into an AML. From May to July 1993, the patient received low-dose cytosine arabinoside chemotherapy. In August 1993, the patient was found to have gone into partial remission with a BM blast count of $10 \%$. Cytogenetic analysis revealed a ring chromosome 1 in 13 of 21 metaphases indicating the persistence of clonal, leukemic cells: (46,XY,r(1)(p35q31)[13]/46,XY[8]) (fig. 1). Only 1 month later, the disease progressed to an AML, subtype M4 (myelomonocytic leukemia) with a BM blast count of $39 \%$ and monocytoid-dif- ferentiated blasts (CD14+, CD33+, CD13+, HLA-Dr+) detectable by flow cytometry. Cytogenetically, disease progression was also indicated by clonal evolution, which consisted of additional numeric aberrations of chromosomes 2, 21 and 22 (45,XY,r(1) (p35q31),+8,-21,-22[7]/r(1)(p35q31),+8,-21[10]/46,XY[4]).

The origin of the ring chromosome could be identified by $G$ banding. The rings were homogeneous in structure. In figure 1 , a small fragment of chromosome 1 can be seen demonstrating that not the whole genetic material was included in the ring, but a fragment (q24-43) was deleted. These small q-arm fragments could be seen in the preparation of August but not in that of September 2003 and might have been lost during the preparation.

The patient received intensive chemotherapy according to the sHAM protocol (hexamethylenamine, Adriamycin, melphalan, methotrexate) and total body irradiation to prepare for allogeneic transplant in December 1993, using his son's HLA-compatible BM. A complete chimerism was established with cells of his son characterized by a phosphoglucomutase 1 (PGM1) type a3a1 isoenzyme type (the patient's PGM1 type was a1a1) [11]. The a3a1 donor PGM1 type was demonstrable at 14 different time points between April 1994 and September 1998 in several cellular fractions (granulocytes, platelets, erythrocytes or lymphocytes) obtained from PB or BM of the patient (data not shown). In January 1997 a relapse of the patient's AML was noted on BM examination with a BM blast cell count of $18 \%$ and a PB blast cell count of $2 \%$. The presence of donor cells in the PB was demonstrable by the PGM1 donor isoenzyme type a3a1. Therefore, the patient could be treated with a DLI-based therapy in combination with LD-AraC and PB-SC without immunosuppressive therapy and immunostimulation with GM-CSF in April 1997 using his son's lymphocytes. After DLI therapy he developed an acute graft versus host reaction of the skin (grade 3) and the intestine; however, he achieved a second remission which has been stable as of January 2005.

The clinical course of the patient was complicated by several transplantation/therapy-associated diseases like EBV-associated pleural polyserositis, a cataract, glaucoma, and stem cell transplantation (SCT)-associated keratoconjunctivitis. Moreover, the patient suffered from herpes infection, diabetes type 2 and osteoporosis.

\section{Material and Methods}

\section{Morphological Examinations}

Cytological and cytochemical examinations of the BM cells were performed by staining the cell smears with Pappenheim solution; peroxidase (POX; rendering yellow stain to granulopoietic cells except myeloblasts) and esterase reactions (macrophages and monocytes strongly react positively) were performed according to standard procedures $[10,12]$.

\section{Immunophenotyping}

Flow-cytometric analysis was employed to determine lineage and maturation of the surface markers. Mononuclear BM cells were incubated with a panel of monoclonal antibodies conjugated with fluorescent dyes [13]. Subsequent analysis was done to determine the proportions of cells and the blast phenotype, according to the manufacturer's instruction (Cytoron Absolute, Ortho Diagnostic Systems). 
Table 1. Patient's course of the disease

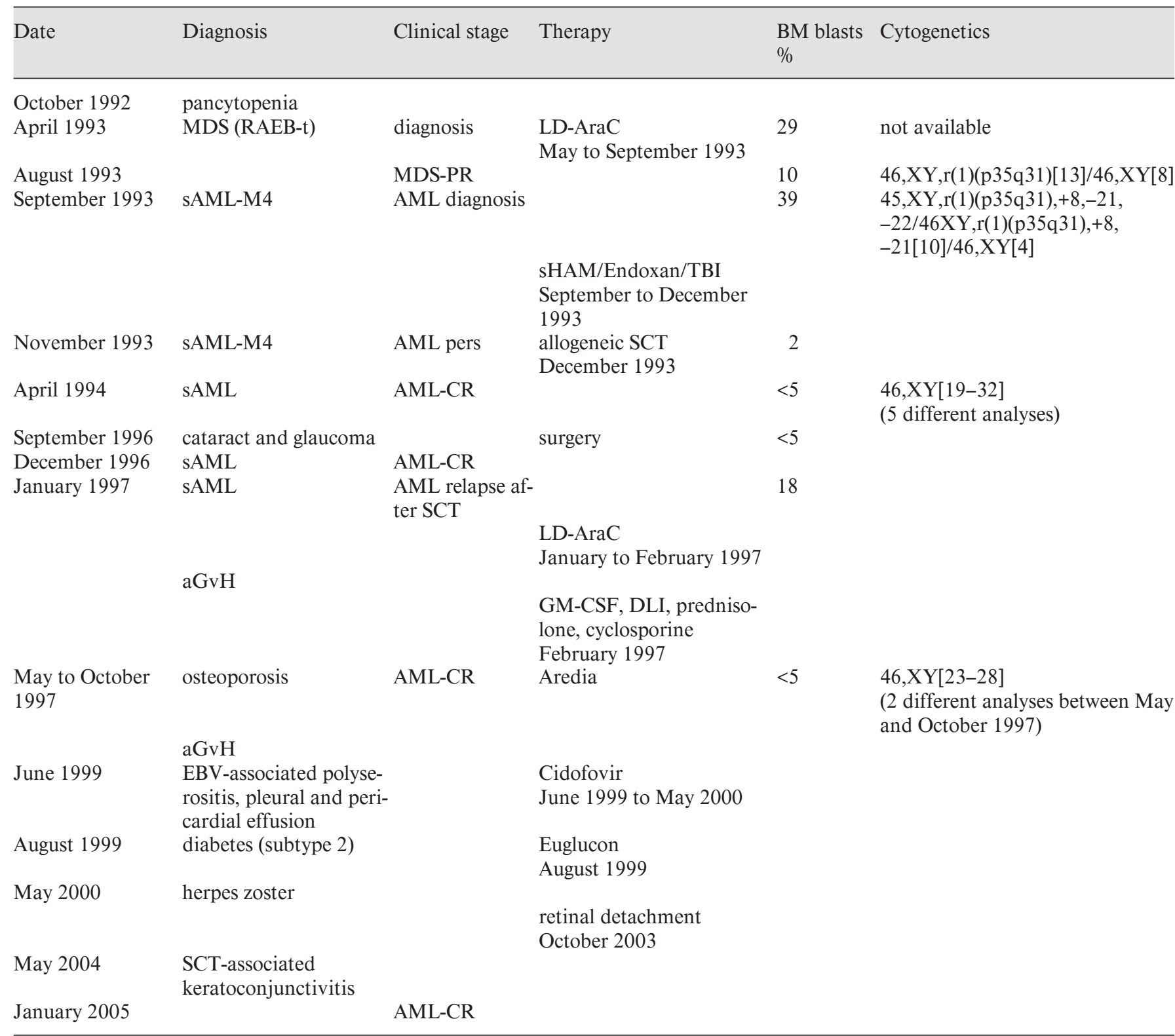

The patient's disease with diagnosis, treatment measures and outcome is demonstrated as related to time. The course of the disease can be seen between October 1992, the diagnosis of pancytopenia, and January 2005, after treatment of AML with BMT, of AML relapse with DLI and of concomitant diseases. The patient is still in remission of AML. PR = Partial remission; CR = complete remission; $\mathrm{sAML}=$ secondary $\mathrm{AML} ; \mathrm{aGvH}=$ acute graft versus host disease; $\mathrm{TBI}$ = total body irradiation; pers = persisting disease.

\section{Cytogenetics}

Cytogenetic techniques were facilitated by incubation of unseparated $\mathrm{BM}$ cells for $48 \mathrm{~h}$ at $37^{\circ} \mathrm{C}$. Metaphase chromosome analysis and Giemsa banding of chromosomes were executed according to standard staining procedures [14].

\section{Discussion}

MDS are disorders characterized by hematopoietic abnormalities involving the clonal hematopoietic progenitor cells resulting in uncontrolled proliferation, differentiation or maturation of hematopoietic cells $[1,3,4]$. The 


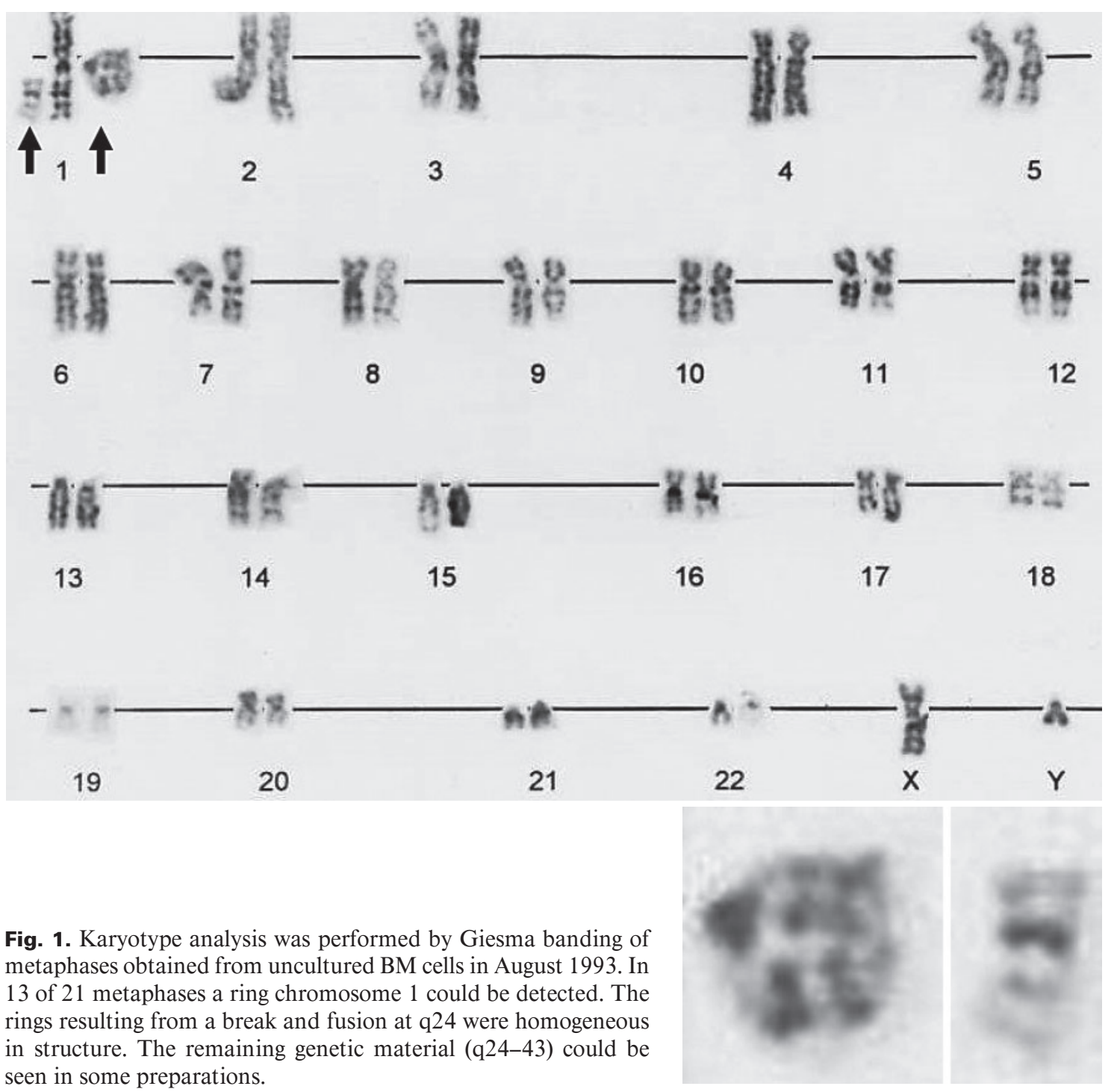

Fig. 1. Karyotype analysis was performed by Giesma banding of metaphases obtained from uncultured BM cells in August 1993. In 13 of 21 metaphases a ring chromosome 1 could be detected. The in structure seen in some preparations.

only potentially curative treatment for these patients is allogeneic hematopoietic SCT [15, 16]. Relapses after transplantation, however, occur and are due to a reemerging of the malignant cell clones, regularly detectable by an increase of blast cells in $\mathrm{PB}$ or BM, reduction of blast phenotypes and/or clonal markers [4, 17-19]. Isoenzyme studies are good means for follow-up analyses of chimerism after SCT. The detection of donor cells in a relapsed patient allows a DLI therapy without preliminary immunosuppression $[11,20]$. Relapses after SCT occur and can be successfully treated by DLI-based therapy as described by others and us [21-23], although the details of DLIbased treatment of a relapse post-SCT in MDS (e.g. with purified donor $\mathrm{T}$ cells or pooled lymphocytes prior che- motherapy) remain to be established [21, 24]. In our case a stable remission could be established by DLI therapy pointing to the crucial and impressive therapeutic efficacy of donor lymphocytes in eradicating tumor burden and establishing a stable remission as already shown in a small group of patients treated in a DLI-based pilot study [23].

The clinical course of the patient was complicated by several SCT and/or graft- versus- host disease-associated side effects; ocular abnormalities like cataracts, keratoconjunctivitis or glaucoma due to microvascular lesions are observed especially in patients conditioned with total body irradiation and cyclosporin A and are more often seen in patients with chronic graft versus host disease [25-27]. Loss of bone mineral density resulting in osteo- 
porosis as well as the development of diabetes mellitus type 2 could be a late effect of SCT [28-31]. EBV or herpes virus infections are still complications in patients after SCT and are often responsible for morbidity and mortality after SCT $[32,33]$. Possibly these infections could be responsible for pleural or pericardial effusions as observed in our patient [34]. Effective prophylactic or preemptive treatment strategies and infection controls after transplantation could help to avoid transplant-related problems [33, 35].

Independent of FAB types cytogenetics contributes important diagnostic and prognostic data in AML and MDS which give clues for therapeutic decisions [17, 36, 37]. Ring chromosomes are rare cytogenetic findings in MDS. Usually they appear in cases with a complex karyotype and are associated with a poor prognosis $[6,7,38]$. Moreover it was shown that clones containing ring chromosomes might be more resistant to chemotherapy than other cytogenetically abnormal clones [7]. It could be demonstrated that the emergence of ring chromosomes correlates well with worsening pancytopenia or transfusion requirements for the patient [38]. In univariate analyses Sole et al. [39] could demonstrate that aberrations at the q-arm of chromosome 1 were associated with an unfavorable prognosis for MDS patients, making patients presenting with such abnormalities good candidates for a more aggressive, curative therapeutic regimen like BMT. Detailed information about the effect of deletions of parts of chromosome 1 on the outcome of MDS patients is still missing.
We describe a case of MDS and secondary AML in a relatively young man with a favorable clinical course, although the cytogenetic findings of a ring chromosome and a complex aberrant karyotype would normally indicate a rather poor prognosis $[1,2,4,36,37]$. Also, there was rapid progression to a secondary acute leukemia, which is often harder to treat than the primary leukemia and has a very short survival time. Despite concomitant SCT-related problems, allogeneic BMT and the DLI treatment for a relapse proved to be a successful therapy, with the patient being in a stable condition for more than 7 years after the initial diagnosis.

To our knowledge ring chromosomes of chromosome 1 were not described in MDS. The clinical course of the patient demonstrates that this ring chromosome 1 contributed to the further clinical course of the disease: the clonal evolution and the fast progression, which could only be cured by BMT with an allogeneic transplant. The relevance of a ring chromosome has not been established; more data need to be collected for establishing the role and impact of a ring chromosome in a patient with MDS and AML.

This case illustrates the already well-established importance of performing cytogenetic examinations additionally to histomorphological techniques in patients with MDS and AML [4, 16, 17, 40].

\section{Acknowledgements}

We would like to thank Ms. K. Hecht and Mr. O. Schiekl for their support and skillful assistance.

\section{References}

1 Mhawesch P, Saleem A: Myelodysplastic syndrome: review of the cytogenetic and molecular data. Crit Rev Oncol Hematol 2001;40: 229-238.

2 Johansson B, Mertens F, Mitelman F: Secondary chromosomal abnormalities in acute leukemias. Leukemia 1994;8:953-963.

3 Sole F, Espinet B, Sanz GF, Cervera J, Calasanz MJ, Luno E, Prieto F, Granada I, Hernandez JM, Cigudosa JC, Diez JL, Bureo E, Marques ML, Arranz E, Rios R, Martinez Climent JA, Vallespi T, Florensa L, Woessner S: Incidence, characterization and prognostic significance of chromosomal abnormalities in 640 patients with primary myelodysplastic syndromes. Grupo Cooperativo Espanol de Citogenetica Hematologica. Br J Haematol 2000; 108:346-356.
4 Schmetzer HM, Poleck B, Duell T, Gerhartz HH, Mittermüller J: Cytogenetics and Southern blot analysis to demonstrate clonality and to estimate prognosis in patients with myelodysplastic syndromes (MDS). Ann Hematol 2000;79:20-29.

5 Gisselsson D, Hoglund M, Mertens F, Johansson B, Dal Cin P, Van den Berghe H, Earnshaw WC, Mitelman F, Mandahl N: The structure and dynamics of ring chromosomes in human neoplastic and non-neoplastic cells. Hum Genet 1999;104:315-325.

6 Yan J, Whittom R, Delage R, Drouin R: A unique clone involving multiple structural chromosome rearrangements in a myelodysplastic syndrome case. Cancer Genet Cytogenet 2003;140:138-144.
7 Yoshida A, Ueda T, Imamura S, Uchida M, Kamada N, Nakamura T: Two types of ring chromosomes found in a patient with myelodysplastic syndrome. Leukemias 1993; 7: 1921-1923.

8 Chen Z, Sandberg AA: Molecular cytogenetic aspects of hematological malignancies: clinical implications. Am J Med Genet 2002;115:130141.

9 De Witte T: Stem cell transplantation for patients with myelodysplastic syndrome and secondary leukemias. Int J Hematol 2000;72: 151-156.

10 Bennett JM, Catovsky D, Daniel MT, Flandrin G, Galton DA, Gralnick H, Sultan C, Cox C: The chronic myeloid leukaemias: guidelines for distinguishing chronic granulocytic, atypical chronic myeloid, and chronic myelomonocytic leukaemias. Proposals by the FrenchAmerican-British Cooperative Leukaemia Group. Br J Haematol 1994;87:746-754. 
11 Holler E, Kolb HJ, Mittermüller J, Kaul M, Ledderose G, Duell T, Seeber B, Schleuning M, Hintermeier-Knabe R, Ertl B, Kempeni J, Wilmanns W: Modulation of acute graft-versushost disease after allogeneic bone marrow transplantation by tumor necrosis factor $\alpha$ $(\mathrm{TNF} \alpha)$ release in the course of pretransplant conditioning: role of conditioning regimens and prophylactic application of a monoclonal antibody neutralizing human TNF $\alpha$ (MAK 195F). Blood 1995;86:890-899.

12 Catovsky D: The Leukemic Cell, ed 2. Edinburgh, Churchill Livingstone, 1991.

13 Rothe G, Schmitz G: Consensus protocol for the flow cytometric immunophenotyping of hematopoietic malignancies. Leukemia 1996; 10:877-895.

14 Seabright M: A rapid banding technique for human chromosomes. Lancet 1971;ii:971972.

15 Cutler CS, Lee SJ, Greenberg P, Deeg HJ, Perez WS, Anasetti C, Bolwell BJ, Cairo MS, Gale RP, Klein JP, Lazarus HM, Liesveld JL, McCarthy PL, Milone GA, Rizzo JD, Schultz KR, Trigg ME, Keating A, Weisdorf DJ, Antin JH, Horowitz MM: A decision analysis of allogeneic bone marrow transplantation for the myelodysplastic syndromes: delayed transplantation for low-risk myelodysplasia is associated with improved outcome. Blood 2004;104: 579-585.

16 Hoffmann WK, Koeffler HP: Myelodysplastic syndrome. Annu Rev Med 2005;56:1-16.

17 Schmetzer H, Poleck B, Mittermüller J, Duell $\mathrm{T}$, Wilmanns W, Gerhartz HH: Clonality as a tool to study the biology and response to therapy in myelodysplastic syndromes. Leukemia 1997;11:660-666.

18 Schmetzer H, Braun S, Wiesner D, Gerhartz $\mathrm{HH}$, Mittermüller J: Gene rearrangements in bone marrow cells of patients with acute myeloid leukemia. Acta Haematol 2000;103:125134.

19 Kern W, Schnittger S: Monitoring of acute myeloid leukemia by flow cytometry. Curr Oncol Rep 2003;5:405-412.

20 Mittermuller J, Kolb HJ, Gerhartz HH, Wilmanns W: Cytotoxic action of low dose Ara-C. Investigations in a marrow grafted patient with relapse. Onkologie 1985;8:168-171.
21 Depil S, Deconinck E, Milpied N, Sutton L, Witz F, Jouet JP, Damaj G, Yakoub-Agha I; Société Française de Greffe de Moelle et Thérapie Cellulaire: Donor lymphocyte infusion to treat relapse after allogeneic bone marrow transplantation for myelodysplastic syndrome. Bone Marrow Transplant 2004;33:531-534.

22 Kolb HJ, Schmid C, Chen X, Woiciechowski A, Roskrow M, Weber M, Guenther W, Ledderose G, Schleuning M: Adoptive immunotherapy in chimeras with donor lymphocytes. Acta Haematol 2003;110:110-120.

23 Schmid C, Schleuning M, Aschan J, Ringden O, Hahn J, Holler E, Hegenbart U, Niederwieser D, Dugas M, Ledderose G, Kolb HJ: Lowdose ARAC, donor cells, and GM-CSF for treatment of recurrent acute myeloid leukemia after allogeneic stem cell transplantation. Leukemia 2004;18:1430-1433.

24 Kolb HJ, Simoes B, Schmid C: Cellular immunotherapy after allogeneic stem cell transplantation in hematologic malignancies. Curr Opin Oncol 2004; 16:167-204.

25 Gullingsrud EO, Krivit W, Summers CG: Ocular abnormalities in the mucopolysaccharidoses after bone marrow transplantation. Longer follow-up. Ophthalmology 1998;105:1099-1105.

26 Tichelli A, Duell T, Weiss M, Socie G, Ljungman P, Cohen A, van Lint M, Gratwohl A, Kolb HJ: Late-onset keratoconjunctivitis sicca syndrome after bone marrow transplantation: incidence and risk factors. European Group or Blood and Marrow Transplantation (EBMT) Working Party on Late Effects. Bone Marrow Transplant 1996;17:1105-1111.

27 Tichelli A: Late ocular complications after bone marrow transplantation. Nouv Rev Fr Hematol 1994;36(suppl 1):S79-S82.

28 Mattano LA Jr: Strategic approaches to osteoporosis in transplantation. Pediatr Transplant 2004;8(suppl 5):51-55.

29 Massenkeil G, Fiene C, Rosen O, Michael R, Reisinger W, Arnold R: Loss of bone mass and vitamin $\mathrm{D}$ deficiency after hematopoietic stem cell transplantation: standard prophylactic measures fail to prevent osteoporosis. Leukemia 2001;15:1701-1705.

30 Sanders JE: Chronic graft-versus-host disease and late effects after hematopoietic stem cell transplantation. Int J Hematol 2002;76(suppl 2):15-28

31 Hoffmeister PA, Storer BE, Sanders JE: Diabetes mellitus in long-term survivors of pediatric hematopoietic cell transplantation. J Pediatr Hematol Oncol 2004;262:81-90.
32 Moss PA, Cobbold M, Craddock C: The cellular immunotherapy of viral infection. Transfus Med 2003;13:405-415.

33 Hebart H, Einsele H: Specific infectious complications after stem cell transplantation. Support Care Cancer 2004;12:80-85.

34 Seber A, Khan SP, Kersey JH: Unexplained effusions: association with allogeneic bone marrow transplantation and acute or chronic graft-versus-host disease. Bone Marrow Transplant 1996;17:207-211.

35 van Esser JW, Niesters HG, van der Holt B, Meijer E, Osterhaus AD, Gratama JW, Verdonek LF, Lowenberg B, Cornelissen JJ: Prevention of Epstein-Barr virus-lymphoproliferative disease by molecular monitoring and preemptive rituximab in high-risk patients after allogeneic stem cell transplantation. Blood 2002;99:4364-4369.

36 Jotterand M, Parlier V: Diagnostic and prognostic significance of cytogenetics in adult primary myelodysplastic syndromes. Leuk Lymphoma 1996;23:253-266.

37 Slovak ML, Kopecky KJ, Cassileth PA, Harrington DH, Theil KS, Mohamed A, Paietta E, Willman CL, Head DR, Rowe JM, Forman SJ, Appelbaum FR: Karyotypic analysis predicts outcome of preremission and postremission therapy in adult acute myeloid leukemia: a Southwest Oncology Group/Eastern Cooperative Oncology Group study. Blood 2000;96: 4075-4083.

$38 \mathrm{Xu}$ J, Cedrone E, Roberts M, Wu G, Gershagen S, Wang N: The characterization of chromosomal rearrangements by a combined microFISH approach in a patient with myelodyplastic syndrome. Cancer Genet Cytogenet 1995; 83:105-110.

39 Sole F, Espinet B, Sanz GS, Cervara J, Calasanz MJ, Luno E, Prieto F, Granada I, Hernandez JM, Cigudosa JC, Diez JL, Bureo E, Marques ML, Arranz E, Rios R, Martinez Climent JA, Vallespi T, Florensa L, Woessner S: Incidence, characterization and prognostic significance of chromosomal abnormalities in 640 patients with primary myelodysplastic syndromes. Br J Haematol 2000;108:346356

40 Mufti GJ: Pathobiology, classification, and diagnosis of myelodysplastic syndrome. Best Pract Res Clin Haematol 2004;17:543-557. 